Supplemental Information for:

\title{
Flux of Total Mercury and Methylmercury to the Northern Gulf of
}

\section{Mexico from U.S. Estuaries}

Clifton S. Buck, ${ }^{\dagger *}$ Chad R. Hammerschmidt, ${ }^{\star}$ Katlin L. Bowman, ${ }^{\star}$ Gary A. Gill, ${ }^{\S}$ and William M.

Landing"

$\dagger$ Department of Marine Science, Skidaway Institute of Oceanography, University of Georgia, 10 Ocean

Science Circle, Savannah, Georgia 31411, United States

${ }^{\ddagger}$ Department of Earth \& Environmental Sciences, Wright State University, 3640 Colonel Glenn Hwy., Dayton, Ohio 45435, United States

§Marine Science Laboratory, Pacific Northwest National Laboratory, Sequim, Washington 98382, United

States

\|Department of Earth, Ocean, and Atmospheric Science, Florida State University, Tallahassee, Florida 32306, United States

7 pages

3 Figures

1 Table 
Figure S1. This conceptual model shows the influence of $\mathrm{Hg}$ input and removal on the estimation of the effective river concentration $\left(C^{*}\right)$. Conservative mixing of $\mathrm{Hg}$ between the measured river end member concentration $\left(C_{0}\right)$ and high salinity waters follow the black mixing line.

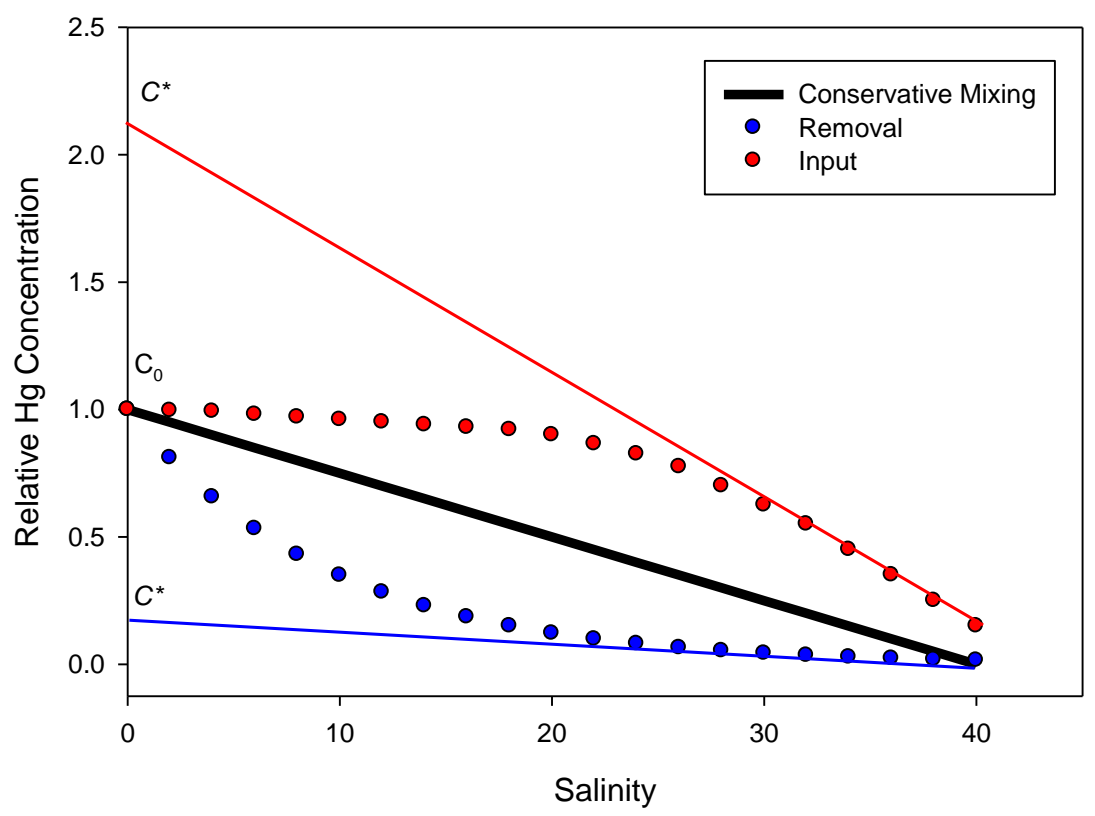


Figure S2. $\Sigma \mathrm{MeHg}$ concentrations in each of the nGOM estuaries during the spring and fall sampling events in 2012. Vertical error bars represent the analytical uncertainty. These distributions with salinity were used to estimate $C^{*}$ values. Shown $C^{*}$ mid values were subsequently used to calculate flux from the estuary to the coastal ocean. Closed symbols and solid lines are for spring and open symbols and dashed lines are for fall.
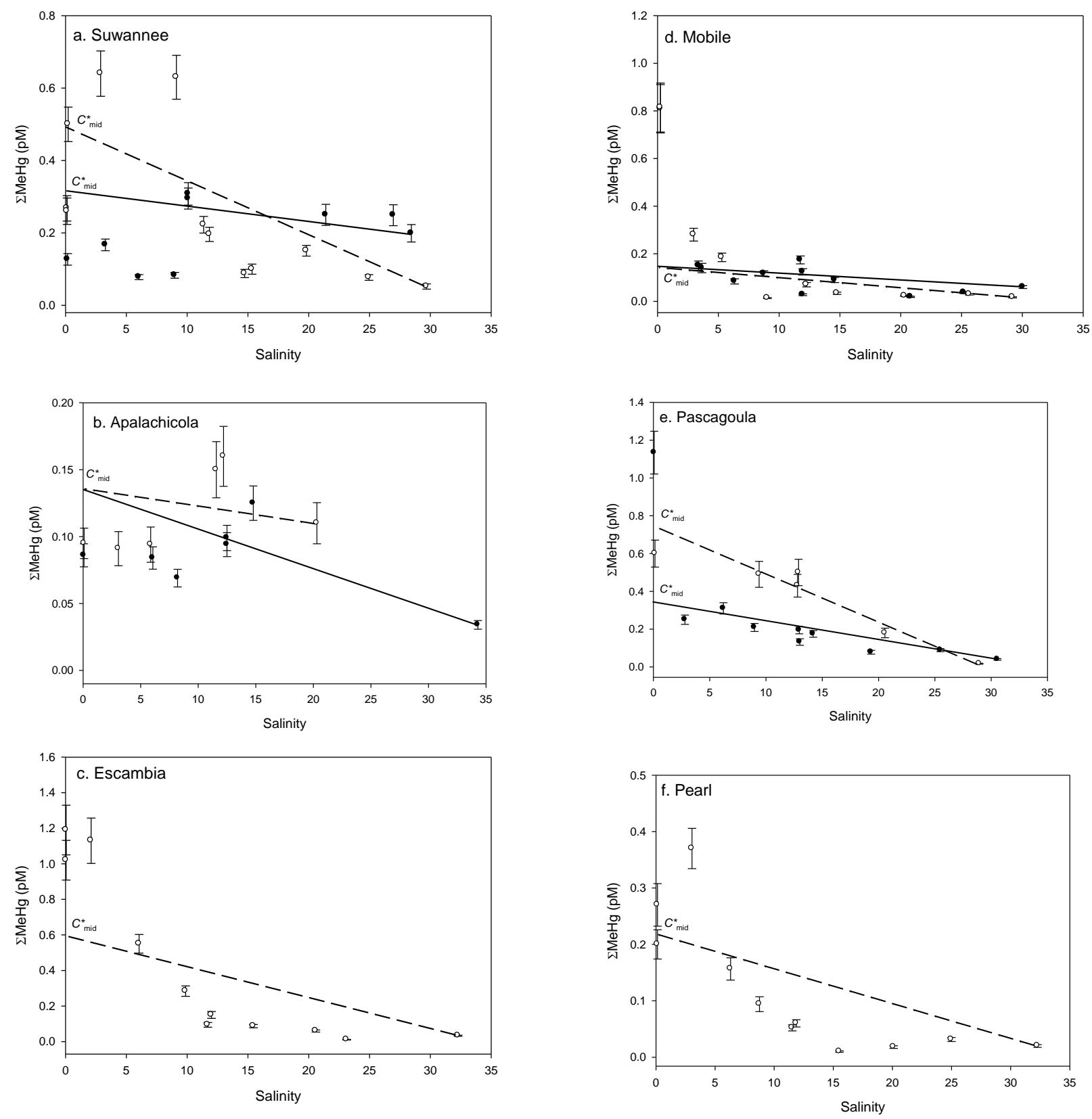

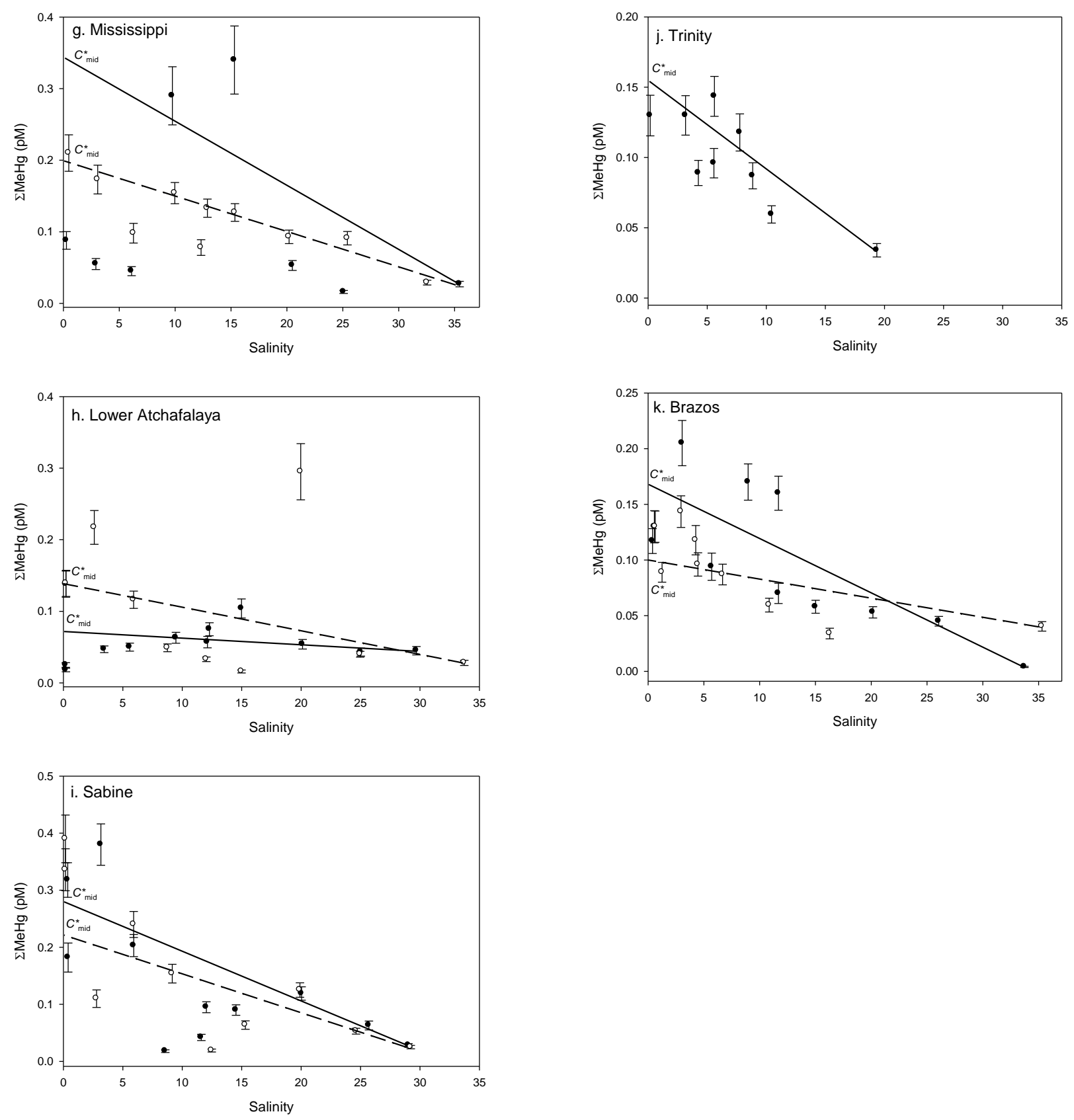
Figure S3. $\Sigma \mathrm{Hg}_{\mathrm{T}}$ concentrations (pM) in each of the $\mathrm{nGOM}$ estuaries during the spring and fall sampling events in 2012. Vertical error bars represent the analytical uncertainty. These distributions with salinity were used to estimate $C^{*}$ values. Shown $C^{*}$ mid values were subsequently used to calculate flux from the estuary to the coastal ocean. Closed symbols and solid lines are for spring and open symbols and dashed lines are for fall.
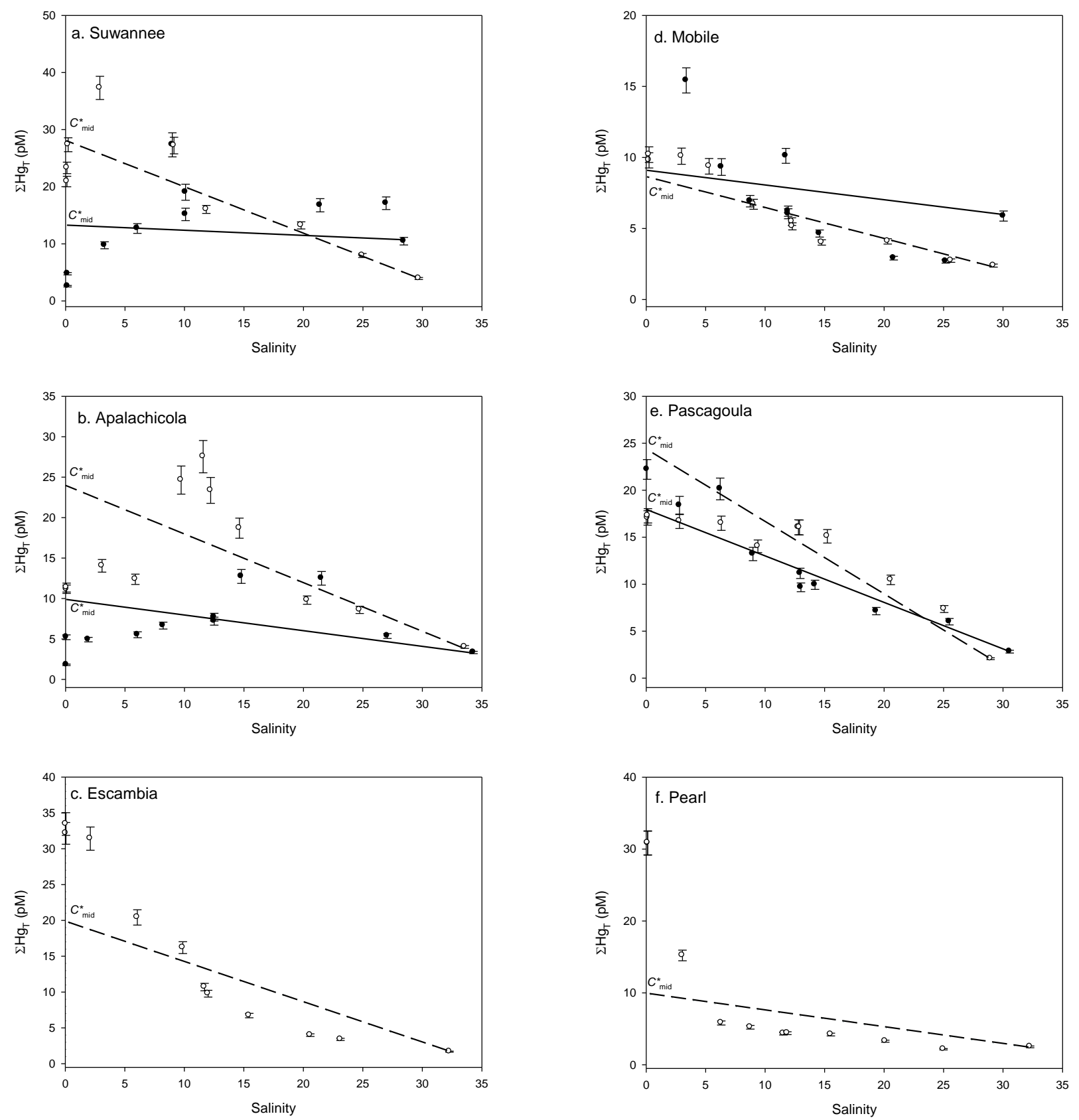

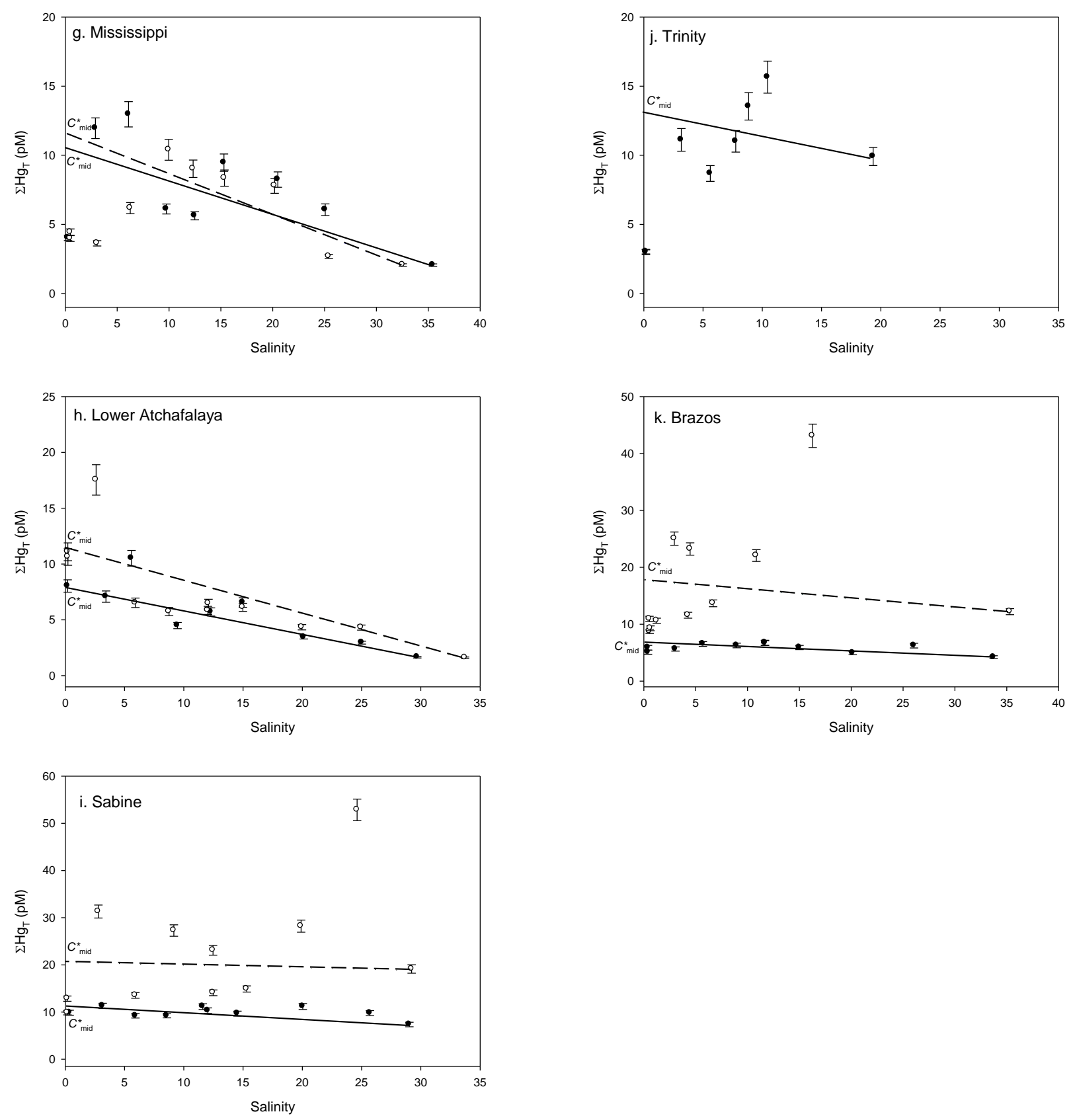
Table S1. Mean discharge $\left(\times 10^{6} \mathrm{~m}^{3} \mathrm{~d}^{-1}\right)$ of northern Gulf of Mexico rivers.

\begin{tabular}{llllll}
\hline River (state) & $\begin{array}{l}\text { Gauge } \\
\text { station }\end{array}$ & Spring & Fall & 2012 & $\begin{array}{l}\text { Long-term } \\
\text { average }\end{array}$ \\
\hline Suwannee (FL) & 02323592 & 9 & 16 & 15 & 18 \\
Apalachicola (FL) & 02359170 & 22 & 19 & 24 & 58 \\
Escambia (FL) & 02376033 & $-^{\mathrm{a}}$ & 5 & 7 & 16 \\
Mobile (AL) & 02470629 & 42 & 25 & 46 & $-^{\mathrm{b}}$ \\
Pascagoula (MS) & 02479000 & 29 & 11 & 27 & 22 \\
Pearl (LA) & 02489500 & $-^{\mathrm{a}}$ & 9 & 24 & 24 \\
Mississippi (LA) & 07374525 & 1145 & 463 & 888 & 1320 \\
L. Atchafalaya (LA) & 07381600 & 250 & 102 & 202 & 309 \\
Sabine (TX) & 08030500 & 22 & 5 & 11 & 11 \\
Trinity (TX) & 08066500 & 23 & $-^{\mathrm{c}}$ & 13 & 20 \\
Brazos (TX) & 08116650 & 22 & 2 & 11 & 18 \\
\hline
\end{tabular}

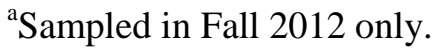

${ }^{\mathrm{b}}$ Not available.

${ }^{\mathrm{c}}$ Sampled in Spring 2012 only. 